\title{
Expression Cloning and Characterization of NSIST, a Novel Sulfotransferase Expressed by a Subset of Neurons and Postsynaptic Targets
}

\author{
Mary A. Nastuk, ${ }^{1}$ Samuel Davis, ${ }^{2}$ George D. Yancopoulos, ${ }^{2}$ and Justin R. Fallon ${ }^{3}$ \\ ${ }^{1}$ Department of Biological Sciences, Wellesley College, Wellesley, Massachusetts 02481, ${ }^{2}$ Regeneron Pharmaceuticals \\ Inc., Tarrytown, New York 10591, and '3epartment of Neuroscience, Brown University, Providence, Rhode Island 02912
}

Synapses are distinguished by localized concentrations of specific proteins, many of which bear the marks of posttranslational processing such as glycosylation and sulfation. One strategy to elucidate this posttranslational tailoring is to identify the enzymes that create these modifications. Monoclonal antibody 3B3 recognizes a carbohydrate-containing epitope expressed on dystroglycan and other constituents of Torpedo electric organ synaptic membranes. We used mAb 3B3 in an immunofluorescence-based expression-cloning method and isolated a cDNA clone conferring mAb-3B3 immunoreactivity to transfected COS cells. The deduced polypeptide has a predicted molecular weight of $51 \mathrm{kDa}$, a type II transmembrane topology, and four potential N-linked glycosylation sites. The polypeptide, which we term NSIST (nervous system involved sulfotransferase), shows extensive, although not complete, homology to a chondroitin-6-sulfotransferase and limited homology to other sulfotransferases. In NSIST-transfected COS cells, ${ }^{35} \mathrm{SO}_{4}$ incorporation and chondroitin-sulfate-like immunoreac- tivity are increased. In vivo, NSIST occurs as a single $2.4 \mathrm{~kb}$ transcript abundant in Torpedo electric organ, moderately expressed in spinal cord and electric lobe, and undetectable in non-neural tissues. Immunohistochemistry shows that NSIST is expressed in a punctate distribution in the innervated portion of electrocytes. In the CNS, NSIST-like immunoreactivity is localized within the somas of motor neurons and neurons of the electromotor nucleus, whereas mAb-3B3 immunostaining is associated with cell surfaces and neuropil. Neuronal NSIST is therefore likely to exert its effects extracellularly; although NSIST is synthesized by neurons, its product, the 3B3 epitope, is found outside neuronal cell bodies. Our evidence indicates that NSIST participates in nervous system specific posttranslational modifications, perhaps including those at synapses.

Key words: synaptic differentiation; posttranslational processing; chondroitin sulfate; sulfotransferase; Torpedo; electric organ; CNS
The establishment and preservation of a synapse demands concerted interplay between the presynaptic neuron and its target (Sanes and Scheller, 1997). This latter cell bears the postsynaptic membrane, a discrete subcellular domain harboring the diverse yet unique array of molecular components supporting rapid and reliable synaptic transmission. Creating and maintaining a synaptic specialization requires modulatory input contributed by both presynaptic and postsynaptic cells and occurring within the context of numerous molecular pathways.

One such mechanism entails the posttranslational modification of synaptic components by selective addition of carbohydrate moieties to them. Such modifications provide structural and functional diversity with a concomitant high degree of specificity. In general, neurons make good use of this molecular diversity; in the CNS, the attachment of carbohydrates to specific surface proteins is a critical determinant for cis- and trans-interactions among cells (Schachner and Martini, 1995) and probably underlies as-

Received Jan. 14, 1998; revised July 6, 1998; accepted July 8, 1998.

This work was supported by the National Institutes of Mental Health and the National Institute of Child Health and Human Development Grants MH53571 and HD23924 (J.R.F.), the Muscular Dystrophy Association (J.R.F.), and the Myasthenia Gravis Foundation (Osserman/McClure postdoctoral fellowship, M.A.N.). We thank M. Bowe for providing mAb3B3, G. Conn for synthesizing oligopeptides, and B. McKechnie for technical assistance.

Correspondence should be addressed to Mary A. Nastuk, Department of Biological Sciences, Wellesley College, 106 Central Street, Wellesley, MA 02181.

Copyright (C) 1998 Society for Neuroscience $\quad 0270-6474 / 98 / 187167-11 \$ 05.00 / 0$ pects of process outgrowth and structural plasticity exhibited by neurons (Emerling and Lander, 1996; Fryer and Hockfield, 1996).

Several lines of evidence indicate a pivotal role for carbohydrates in neuromuscular synaptogenesis. $N$-acetylgalactosaminylterminated saccharides are selectively localized to neuromuscular junctions, where they are thought to modulate synaptic differentiation (Martin and Sanes, 1995). A key synthetic enzyme, $N$-acetylgalactosaminyl transferase, also has a synaptic localization (Scott et al., 1990). Additional synapse-specific carbohydrates include a glycosylation-dependent epitope of entactin (Chiu and Ko, 1994) as well as certain heparan sulfate proteoglycans (Anderson et al., 1983; Bayne et al., 1984; Sanes et al., 1986). Finally, muscle-derived chondroitin sulfate proteoglycans (CSPGs) are likely to play a central role in acetylcholine receptor (AChR) clustering (Mook-Jung and Gordon, 1995; Bowen et al., 1996).

Sulfation often acts in concert with glycosylation to create the unique structural features associated with discrete physiological functions of the parent molecule. For example, sulfation and glycosaminoglycan chain elongation are thought to be coupled in muscle cells, and such linkage may be important for AChR clustering on myotubes (Bowen et al., 1996). Thus, glycosylation and sulfation are ideally suited to play a major cooperative role in modifying and maintaining synaptic specializations.

One strategy for examining the posttranslational processing of synaptic proteins entails identifying and characterizing the participative enzymes. In the present study, we used the knowledge that $\mathrm{mAb} 3 \mathrm{~B} 3$, previously developed in this laboratory (Bowe et 
al., 1994), recognizes a sialic acid-containing epitope borne by a group of membrane-associated synaptic glycoproteins in Torpedo electric organ, among them $\alpha$ - and $\beta$-dystroglycan. We used an immunofluorescence-based expression-cloning strategy to identify an enzyme that is essential for creating this epitope. The enzyme has strong homologies to a chondroitin-6-sulfotransferase (C6ST; Fukuta et al., 1995), which can also catalyze the sulfation of sialyl lactosamine oligosaccharides (Habuchi et al., 1997). Because this enzyme is enriched in the Torpedo nervous system, we have named it NSIST (nervous system involved sulfotransferase). Furthermore, we show that NSIST is selectively expressed by Torpedo motor neurons and that its product, the 3B3 epitope, is associated with neuronal surfaces and neuropil in the CNS. Thus, NSIST is a novel sulfotransferase that is likely to function within the nervous system, in which it could execute specific structural and functional modifications of synaptic components.

\section{MATERIALS AND METHODS}

Expression cloning. An oligo-dT-primed cDNA library was prepared from Torpedo electric organ polyA mRNA and ligated into the Bst XI cloning site of the expression vector pCMX (Davis et al., 1991). Recombinants in the library had an average insert size of $1.5 \mathrm{~kb}$. Approximately $1 \mu \mathrm{g}$ of the library was transfected using DEAE-dextran (Sambrook et al., 1989) into COS cells plated onto single-welled chamber slides (Nunc, Roskilde, Denmark; $\sim 3.0 \times 10^{5}$ cells per slide). Two days later, intact cultures were immunostained with mAb $3 \mathrm{~B} 3$ and brightly stained cells collected with a glass micropipette. For technical reasons, this harvest included $\sim 5-10$ neighboring cells.

Plasmid DNA was extracted from each harvest by incubation for $1 \mathrm{hr}$ at $55^{\circ} \mathrm{C}$ in $200 \mu$ l extraction buffer $(100 \mathrm{~mm}$ EDTA, $0.5 \%$ SDS, $10 \mathrm{mg} / \mathrm{ml}$

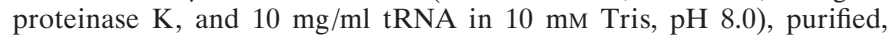
amplified in Escherichia coli, and retransfected into COS cells. Clonal cDNA was obtained after two or three rounds of repeated selection and enrichment.

Antibodies. Monoclonal antibody 3B3 was produced and characterized as described in Bowe et al. (1994) and used as an undiluted hybridoma supernatant or as purified IgG, with similar results. Monoclonal antibody CS-56 (anti-chondroitin sulfate) was obtained from Sigma (St. Louis, $\mathrm{MO}$ ). Anti-agrin antibody 6D4 was used as an undiluted hybridoma supernatant (Fallon et al., 1985).

For production of the anti-NSIST antisera, a synthetic peptide corresponding to the region TPPKKGGTEKFP of the NSIST sequence (Fig. 1) was synthesized bidirectionally so that a cys-gly linker could be added at either end, and the resulting mixture was then conjugated to purified protein derivative (PPD). Polyclonal antisera were produced in rabbits (CoCalico); antisera RG211 and RG212 were produced by two different rabbits that had been immunized with the same peptide mixture.

Immunostaining of COS cells. For mAb 3B3 immunostaining, transfected COS cell monolayers were washed in HEPES-buffered minimal essential medium (MEM-H), blocked in MEM-H containing $1 \%$ bovine serum albumin and 10\% normal horse serum, and incubated in mAb3B3 followed by rhodamine-conjugated horse anti-mouse $\operatorname{IgG}_{3}$ (1:100; Fisher Scientific, Houston, TX). Cultures were fixed in $100 \%$ methanol for 5 min at $-20^{\circ} \mathrm{C}$, air-dried, and mounted in Citifluor (Pella, Redding, CA). Slides were viewed with rhodamine optics on a Zeiss Axioplan microscope.

For anti-NSIST immunostaining, transfected cells were first permeabilized in $100 \%$ methanol for $5 \mathrm{~min}$ at $-20^{\circ} \mathrm{C}$, then blocked and treated as above (but with $10 \%$ normal goat serum). Cells were then incubated with RG211 antiserum or nonimmune serum (1:100), followed by fluorescein-conjugated goat anti-rabbit Ig (1:100).

Immunostaining of frozen sections. Cryostat sections $(12 \mu \mathrm{m})$ of freshfrozen Torpedo electric organ, electric lobe, spinal cord, and skeletal muscle were fixed for $5 \mathrm{~min}$ at room temperature in $1 \%$ paraformaldehyde in PBS, rinsed in PBS, and blocked for $1 \mathrm{hr}$ in PBS containing 1\% nonfat dry milk and $10 \%$ normal goat or horse serum (depending on the secondary antibody used). Sections were incubated in mAb 3B3, mAb 6D4 (undiluted or 1:10 hybridoma supernatant), RG212 (1:500), or nonimmune control serum diluted in PBS containing 1\% NFDM, $1 \%$
TCTTACTGCTTACCGAAATTAATACGACTCACTATAGGGAGACCCAAGCTTCTAGAGATC CCTCGACCTCGAGATCCATTGTGCTCTAAAGCTGGCAGTGAGCGAGTCGCTGTGGATCCC CTCCCTCCGGGCTGCACTCAGTCGCCACGATGCTTGCGGAAAAGAAGGCACATCCAAGCC TAGATCTGCACCGAGCTGCTCGCCTGGTGATGTGAATCCAATCTGCTCGCCTTCACACGT CGACCACMAGTTCCTCTGCCCGAGGACTGGAGARTGCTGATGTGACCTTGCCTTCACCG GGAGACTGGCCGAGCGCTGGCATGGGACCAGGCTCAC AAGCAACGCCTCTGTACCTAGGGACATCCCGTGCAGCTCTGAGTCAGGAGTCCAGCCTCA AAGCCAGTAGCAATGAAAATGAGAAGCAAATATGCAATTATTCTGTTTTTTGTTGTTGCT \begin{tabular}{llllllllllllllll}
$M$ & $K$ & $M$ & $R$ & $S$ & $K$ & $Y$ & $A$ & $I$ & $I$ & $L$ & $F$ & $F$ & $V$ & $V$ & $A$ \\
\hline
\end{tabular}

CTIGTGATCATTGAAAAAGAAAGGAACATAATTTCAAGGGTGTCTGACAAGTTTACACTG

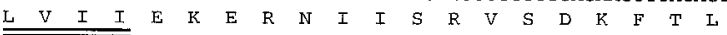
AAATTCCCACACGCGGAATCTGTGGCGCCAAACAACACGATTTCTGCCAGATCCTTGACG $\begin{array}{llllllllllllllllllll}K & F & P & H & A & E & S & V & A & P & N & N & T & I & S & A & R & S & L & T\end{array}$ AAGAATAACTCCCTGCTCGCCAACTCAGTCGCTGCCGTCTGGAAGCTGCTAAAGGCCCGA $\begin{array}{lllllllllllllllllllll}\text { K } & N & N & N & \text { S } & \text { L } & \text { L } & \text { A } & \text { N } & S & V & A & \text { A } & \text { V } & \text { W } & K & \text { L } & \text { L } & \text { K } & \text { A } & R\end{array}$ AGAAGCTACTCGTCACTGCAAAGCGCAGCCAGCAGTGATGTGAGGAAGGTCTTGAAGGGC $\begin{array}{lllllllllllllllllllll}R & S & Y & S & S & L & Q & S & A & A & S & S & D & V & R & K & V & L & K & G\end{array}$ CGGAAGCACTIGTIGCTGATGGCGACTACCAGGACTGGTTCTTCCTPTGTGGGCGAGTTC $\begin{array}{llllllllllllllllllll}R & K & H & L & L & L & M & A & T & T & R & T & G & S & S & F & V & G & E & F\end{array}$ TTCAACCAGAACAACGACATCTTCTACCTGTTIGAACCGCTGTGGCACGTGGAGAAGACG $\begin{array}{lllllllllllllllllllll}F & N & Q & N & N & D & I & F & Y & L & F & E & P & L & W & H & V & E & K & T\end{array}$ GTCACCTTTGAGCCGGGTGGAATGAACGCTGTGGCTTCTTCCATCATTTACCGCGATGTG

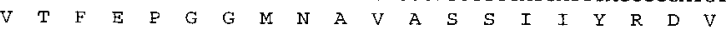
GTGCAGCAGTTGATGCTGTGCGACCTGTACACACTGGAAAATTTCCTATTCCCGATGGCC $\begin{array}{llllllllllllllllllll}V & Q & Q & L & M & L & C & D & L & Y & \text { T } & \text { L } & E & \text { N } & F & \text { L } & F & \text { P } & \text { M } & A\end{array}$

GACCGCCATCTCACAGGCATCCTGTTCCGTCGAGGCTCCAGCAAGTCCTTGTGCGAGGGA $\begin{array}{llllllllllllllllllll}D & R & H & L & T & G & I & L & F & R & R & G & S & S & K & S & L & C & E & G\end{array}$ GAGGTTTGCACACCACCTAAGAAAGGCGGGACCGAGAAGTTTCCCTGTCGGCTACGCGAC

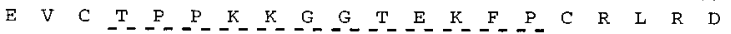
TGTGGGCTCCTCAATTTGACCCTGGCCACTCAGGCATGCCTCCAAAAGCAGCACGTGGCC $\begin{array}{lllllllllllllllllllll}C & G & \text { L } & \text { L } & \text { N } & \text { L } & \text { T } & \text { L } & \text { A } & \text { T } & \& & \text { A } & \text { C } & \text { L } & Q & \text { K } & Q & \text { H } & \text { V } & \text { A }\end{array}$ ATAAAGACCGTCCCCCTGAGGCAGCTGGAGTTTCTCCGGCCACTGGTGGAGGACTTCAGG $\begin{array}{llllllllllllllllllllll}I & K & T & V & P & L & R & Q & L & E & F & L & R & P & L & V & E & D & F & R\end{array}$ ATCAACCTGAAGATCATTCAGTTGGTGCGTGACCCCAGGGCGGTGCTGGCTTCAAGGATG $\begin{array}{llllllllllllllllllll}I & N & L & K & I & I & Q & L & V & R & D & P & R & A & V & L & A & S & R & M\end{array}$ GTGGCCTTCCCCAGCAAGTACAATGCGTGGAAGAAGTGGGCCAACGAAGGGAGAGTGCCG $\begin{array}{llllllllllllllllllll}V & A & F & P & S & K & Y & N & A & W & K & K & W & A & N & E & G & R & V & P\end{array}$ GACGACGACGAGGTCGGCAAGATCCGAGGGAACTGCGAGAACCTCCGGGCCACCGCACAA $\begin{array}{llllllllllllllllllll}D & D & D & E & V & G & K & \text { I } & \text { R } & \text { G } & \text { N } & \text { C } & \text { E } & \text { N } & \text { L } & \text { R } & \text { A } & \text { T } & \text { A } & Q\end{array}$ CTIGGCATCAGTCAGCCGCCTIGGCTGAAGGATCGCTTCCTGCTGATGCGTTACGAGGAC

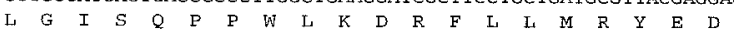
ATTGCGCIGGAGCCCGTGAAGAGGGCGCAGGAGATGTACCGCTITTCCGGCATTCCCATG $\begin{array}{lllllllllllllllllllll}I & \mathrm{~A} & \mathrm{~L} & \mathrm{E} & \mathrm{P} & \mathrm{V} & \mathrm{K} & \mathrm{R} & \mathrm{A} & \mathrm{Q} & \mathrm{E} & \mathrm{M} & \mathrm{Y} & \mathrm{R} & \mathrm{F} & \mathrm{S} & \mathrm{G} & \mathrm{I} & \mathrm{P} & \mathrm{M}\end{array}$ ACACCCGAGGTCAAAAAGTGGATCTAGGAAAACACCCAAG'TTCCAAGGCCAGCAACAAC $\begin{array}{lllllllllllllllllllll}T & \mathrm{P} & \mathrm{E} & \mathrm{V} & \mathrm{K} & \mathrm{K} & \mathrm{W} & \mathrm{I} & \mathrm{Y} & \mathrm{E} & \mathrm{N} & \mathrm{T} & \mathrm{Q} & \mathrm{V} & \mathrm{S} & \mathrm{K} & \mathrm{A} & \mathrm{S} & \mathrm{N} & \mathrm{N}\end{array}$ ATCTACTCAACGCACAAAATCTCCTCGGAGCAGT'TTGAGAAGTGGCGGCTTGGTCTGCCG $\begin{array}{llllllllllllllllllll}I & \mathrm{Y} & \mathrm{S} & \mathrm{T} & \mathrm{H} & \mathrm{K} & \mathrm{I} & \mathrm{S} & \mathrm{S} & \mathrm{E} & \mathrm{Q} & \mathrm{F} & \mathrm{E} & \mathrm{K} & \boldsymbol{W} & \mathrm{R} & \mathrm{L} & \mathrm{G} & \mathrm{L} & \mathrm{P}\end{array}$ TTCAAGATAGCCAGAGTGGTCCAACAGGTGTGTGAGCCGGCAATGAAACTGTTCGGCTAC $\begin{array}{lllllllllllllllllllll}F & K & I & A & R & V & V & \& & Q & V & C & E & P & A & M & K & L & F & G & Y\end{array}$

AAGTTGGTGAAGGACGCAGCAACCCIIGCCAACAGGTCTGCCAGCCTGCTGGAGAACAGG $\begin{array}{llllllllllllllllllll}K & L & V & K & D & A & A & T & L & A & N & R & S & A & S & L & L & E & N & R\end{array}$ AACTTTTGGATAACCTAACCTCGGAAGAAGTTGCAATCGTCTTCGAGCAGCCGAAGCAGT N $F$ W $I$ T

GAGAGATAAAACTTGAATCTTCTTGGACCTTCTACAGAAGTGCCAAGCCAATACGACATC TCCTGGATGGATGTGCAATGGCCTGACCAGGCACCACAAGGACAAAACAGTTGCCTTGAC AATGGAATCACACAAATGAAGCACACAAATGAGGGATTTATTTATTAAGGAAAGATTAT AATGGAATCACACAAATGAAGCACACAAATGAGGGATTTATTTATTAAGGAAAAGATTAT
TTTTATGATGATTTTATAAAGATTTAGCATGGTGTTGAGGCTAGATGGGGACAGGGTTG TTTTATGATGATT

60

180

240

300 360 20 480

Figure 1. Nucleotide and deduced amino acid sequence of NSIST. The putative transmembrane domain/signal sequence is underlined with a double solid line. Potential $\mathrm{N}$-linked glycosylation sites are underlined with single solid lines. The amino acid sequence used to generate a synthetic peptide antigen is underlined with a dotted line. This sequence has been deposited in GenBank, accession number AF079875. 

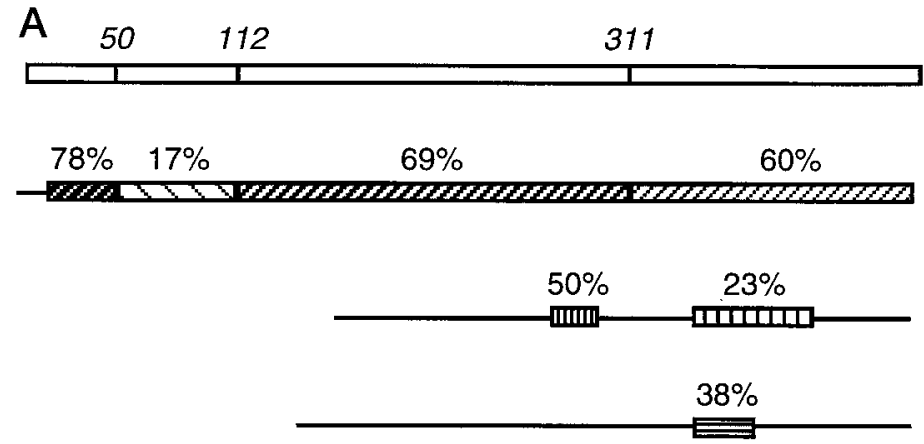

NSIST (451 aa)

C-6-ST (458 aa)

DHEA-ST (284 aa)

Flav. ST (311 aa)
Scale: $\longrightarrow=50$ aa

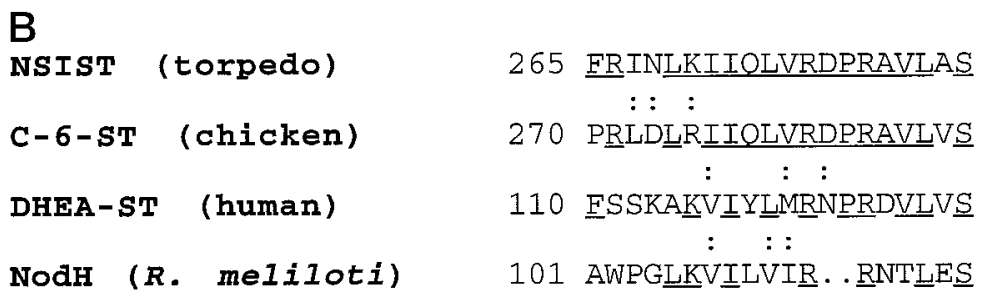

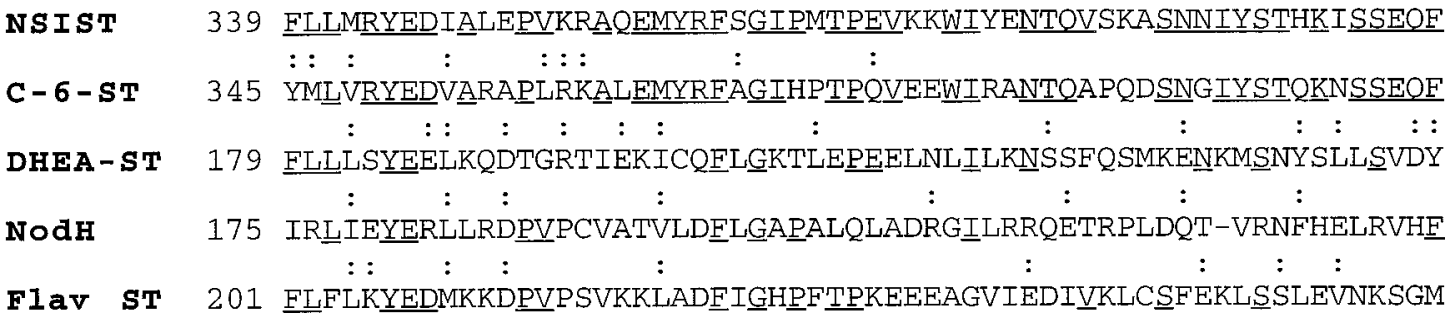

Figure 2. Homologies between NSIST and sulfotransferases. A, Percent sequence identity of chick C6ST (Fukuta et al., 1995), human dehydroepiandrosterone (DHEA ST; Otterness et al., 1995), and Flaveria chloraefolia flavonol 4'-sulfotransferase (Flav. ST; Varin et al., 1992) as compared with NSIST. Major domains of NSIST, defined by their percent identity to C6ST, are indicated at top by amino acid residue numbers. $B$, Partial amino acid sequence alignment of NSIST with chick C6ST, human DHEA ST, lipooligosaccharide sulfotransferase (NodH; Roche et al., 1991) from R. meliloti, and flavonol ST from $F$. chloraefolia. The amino acids conserved among NSIST and at least one sulfotransferase are underlined. Homologous residues shared by NSIST and other sulfotransferases are indicated with a colon above the relevant residue.

normal goat or horse serum, and $0.1 \%$ Triton X-100. Sections were washed in PBS with $0.1 \%$ Triton X-100 and incubated with either rhodamine-conjugated goat anti-mouse $\mathrm{IgG}_{3}$ (for $\mathrm{mAb3B}$; Fisher), or biotinylated goat anti-rabbit Ig followed by streptavidin-fluorescein (for RG212; Vector Laboratories, Burlingame, CA). Some sections were counterlabeled with rhodamine- $\alpha$-bungarotoxin (rh-BTx; Molecular Probes, Eugene OR). Sections were post-fixed and mounted as described above.

Northern blotting. Total RNA was extracted from Torpedo tissues using a guanidinium thiocyanate phenol-chloroform single-step extraction kit (Stratagene, La Jolla, CA) followed by a second phenol-chloroform extraction. RNA samples $(10 \mu \mathrm{g} /$ lane $)$ were electrophoresed, blotted onto Hybond- $\mathrm{N}^{+}$nylon membrane (Amersham, Arlington Heights, IL), and probed with a [ $\left.{ }^{32} \mathrm{P}\right] \mathrm{dCTP}-$ labeled cDNA encompassing nucleotides 77 to 849 of the NSIST insert (Amersham Rediprime System). Hybridization was performed in Rapid-hyb buffer (Amersham) for $2 \mathrm{hr}$ at $65^{\circ} \mathrm{C}$. Membranes were washed for $20 \mathrm{~min}$ at $20^{\circ} \mathrm{C}$ in $2 \times$ SSC with $0.1 \%$ SDS, then for $15 \mathrm{~min}$ at $65^{\circ} \mathrm{C}$ in $0.5 \times \mathrm{SSC}$ with $0.1 \%$ SDS, then for $10 \mathrm{~min}$ at $65^{\circ} \mathrm{C}$ in $0.1 \times$ SSC with $0.1 \%$ SDS. Binding was analyzed with a PhosphorImager (Molecular Dynamics, Sunnyvale, CA).

Immunoblotting. Postsynaptic and nonsynaptic membranes were isolated from Torpedo electric organ on sucrose gradients as previously described (Bowe et al., 1994). The postsynaptic membranes were used either intact or after stripping at pH 11 (Neubig et al., 1979). To prepare COS cell membranes, cultures were scraped into harvesting buffer $(1 \mathrm{~mm}$ EDTA, $1 \mathrm{~mm}$ EGTA, $0.085 \mathrm{U} / \mathrm{ml}$ aprotinin, $1.8 \mathrm{mg} / \mathrm{ml}$ benzamidine, 0.5 $\mu \mathrm{g} / \mathrm{ml}$ leupeptin, $0.7 \mu \mathrm{g} / \mathrm{ml}$ pepstatin, and $1 \mathrm{~mm}$ PMSF in PBS), homogenized, and spun at $500 \times g$ to pellet nuclei. Membranes were pelleted from the supernatant at $100,000 \times g$.

Samples were separated on 5-15\% SDS-PAGE gels and transferred to nitrocellulose. The membranes were then blocked in PBS containing $10 \%$ nonfat dry milk, $10 \%$ goat serum, and $0.1 \%$ Tween 20 , and incubated in RG212 or CS-56. In all cases nonimmune IgG was used as a control. Bound Ig was detected with a Vectastain ABC kit as per the supplier's protocol (Vector Laboratories) or with ${ }^{125}$ I-protein $\mathrm{A}\left(1 \times 10^{5}\right.$ $\mathrm{cpm} / \mathrm{ml}$; New England Nuclear, Boston, MA).

Radiolabeled sulfate incorporation. COS cells were plated onto $10 \mathrm{~cm}$ dishes and transfected with plasmid encoding NSIST or low-affinity nerve growth factor receptor (LNGFR). One day later, ${ }^{35} \mathrm{SO}_{4}(100 \mu \mathrm{Ci} / \mathrm{ml}$; New England Nuclear) was added. After overnight incubation, membrane and cytosolic COS fractions were harvested (see above). Incorporated ${ }^{35} \mathrm{~S}$ was quantitated by triplicate scintillation counting of samples that had been normalized for protein content (Micro BCA protein assay kit; Pierce, Rockford, IL). 


\section{RESULTS}

\section{Expression cloning of NSIST}

Previous work in this laboratory showed that mAb $3 \mathrm{~B} 3$ recognizes a carbohydrate-containing epitope abundant in Torpedo electric organ synaptic membranes (Bowe et al., 1994). We reasoned that we could use mAb 3B3 as a tool to clone the enzyme(s) responsible for creating this epitope. In preliminary immunofluorescence experiments we found that mAb $3 \mathrm{~B} 3$ did not bind to untransfected COS cells. Thus, we used mAb $3 \mathrm{~B} 3$ in an antibodybased expression-cloning scheme to screen COS cells that had been transfected with a cDNA library derived from Torpedo electric organ. This method allowed us to select for particular subcellular localizations (e.g., cell surface or intracellular) of the expressed epitopes.

First-round transfection of COS cells with electric organ library yielded approximately one positive cell per $3 \times 10^{6}$ total cells plated. Positive cells showed bright, punctate, surface immunolabeling with mAb3B3 (see Fig. 5A). After two additional rounds of plasmid selection and amplification we obtained a clonal cDNA that, when transfected into COS, resulted in many 3B3-positive cells per slide. Based on our characterization and on sequence homology (see below), we have named the product of this clone NSIST.

\section{Sequence analysis of NSIST indicates that it encodes a sulfotransferase}

The nucleotide and deduced polypeptide sequences of NSIST are shown in Figure 1. The cDNA contains 2052 nucleotides, with an open reading frame beginning at a putative translation initiation site. This open reading frame encodes 441 amino acid residues and is likely to be complete because it is flanked by in-frame stop codons and untranslated, noncoding sequence.

The deduced amino acid sequence predicts a protein with a molecular weight of $51 \mathrm{kDa}$. A putative signal peptide of 14 amino acids begins at residue 7 ; this hydrophobic region constitutes the sole predicted transmembrane domain. In addition, the protein sequence includes four potential sites of N-linked glycosylation as well as a cysteine-enriched central region.

Database searches using the BLAST algorithm (Altschul et al., 1990) revealed that the deduced NSIST polypeptide sequence has varying degrees of homology to at least three distinct sulfotransferases. NSIST shows the strongest homology to C6ST, cloned from chick chondrocytes (Fukuta et al., 1995). Overall, the two amino acid sequences are $58 \%$ identical (Fig. $2 A$ ). The NSIST and C6ST sequences show $78 \%$ identity over a 33-amino acid domain near the amino terminal. There is a 200-amino acid central region with $69 \%$ identity, and the N-terminal 137 amino acids of the two polypeptides are $60 \%$ identical. In contrast, one domain of NSIST (amino acids 44-106) is only 17\% identical to the C6ST sequence.

NSIST also shows a more limited homology to other sulfotransferases (Fig. 2B). Two regions of 20 and 60 amino acids within the NSIST sequence have weak but consistent identity (35 and 17\%, respectively) with a bacterial lipooligosaccharide sulfotransferase (Roche et al., 1991) as well as another family of sulfotransferases that include alcohol and hydroxysteroid sulfotransferases (50 and 23\%; Rikke and Roy, 1996). The second of these regions also shows $38 \%$ identity to part of a plant flavonol sulfotransferase (Varin et al., 1992). Taken together, these homologies suggest that NSIST is a sulfotransferase, a possibility that we sought to test further (see below).
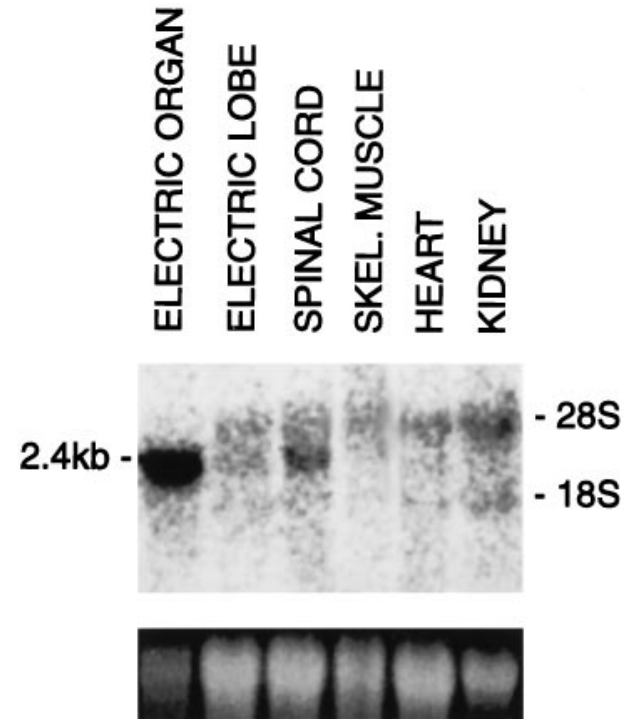

Figure 3. NSIST mRNA expression in adult Torpedo tissues. Each lane of the Northern blot contains $10 \mu \mathrm{g}$ of total RNA from electric organ, electric lobe with surrounding midbrain, spinal cord, skeletal muscle, heart, or kidney. A single NSIST transcript was detected with an estimated size of $2.4 \mathrm{~kb}$. The transcript is most abundant in electric organ, moderately expressed in electric lobe and spinal cord, and not detected in the other tissues shown. Similar results were obtained in three experiments from different animals. The bands at $28 \mathrm{~S}$ and $18 \mathrm{~S}$ are likely to represent nonspecific binding to ribosomal RNA. Ethidium bromide staining of the RNA gel (bottom panel) shows that loading is similar across lanes, with the exception of a slight underloading for electric organ.

\section{NSIST mRNA is abundant in particular regions of the Torpedo nervous system}

We next determined the size and tissue distribution of the NSIST transcript in Torpedo. As shown in Figure 3, NSIST is expressed as a single $2.4 \mathrm{~kb}$ mRN. Transcript expression varies for different tissues: levels are highest in electric organ, with lower levels in spinal cord and electric lobe. The signal for electric organ is likely to represent an underestimate of actual transcript levels because of slight underloading of the RNA from that tissue. We did not detect any signal in the other tissues examined, including skeletal muscle, heart, and kidney. Thus, NSIST mRNA is selectively expressed in the nervous system. We obtained comparable results in experiments using mRNA from three different rays. Furthermore, a band of comparable size was observed when total RNA from NSIST-transfected COS cells was similarly probed (data not shown).

\section{The NSIST protein is tightly associated with membranes of Torpedo electric organ}

To characterize the NSIST protein, we raised polyclonal antisera against a synthetic peptide corresponding to part of the central cysteine-rich sequence (Fig. 1). Two antisera, RG211 and RG212, were used in immunoblotting and immunostaining to reveal NSIST's tissue and subcellular localization, biochemical properties, and relationship to the $3 \mathrm{~B} 3$ epitope in electric organ and COS cells.

Immunoblotting of membrane fractions from Torpedo electric organ (Fig. 4A, lanes 1,3) showed that NSIST migrates with an apparent molecular weight of $136 \mathrm{kDa}$. The band appears slightly fuzzy, consistent with glycosylation of the core protein at one or more of the predicted sites. NSIST was resistant to extraction from these membrane fractions at $\mathrm{pH} 11$ (Fig. 4A, lane 2), 
A.

\section{Torpedo electric organ:}

Membrane fraction

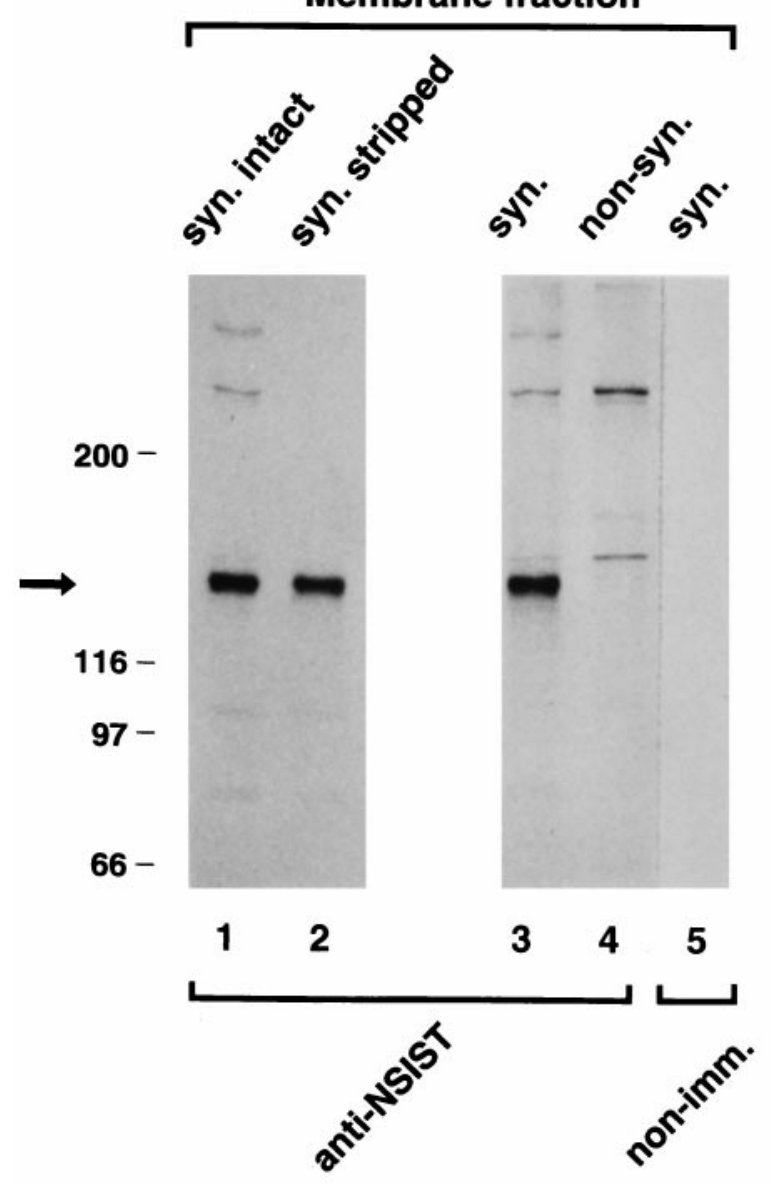

suggesting that it is tightly membrane-associated. Finally, NSIST is abundant in fractions enriched in synaptic components as compared with those enriched in nonsynaptic components (Fig. $4 A$, lane 4$)$. However, because these membrane fractions are isolated on the basis of sedimentation in sucrose gradients (Neubig et al., 1979), this selective association should not be taken to indicate that NSIST is uniformly associated with AChR-rich, postsynaptic membranes; rather, the NSIST-containing membranes may also include certain copurifying Golgi and/or postGolgi membranes. Indeed, our immunolocalization indicates that NSIST is associated with only a subpopulation of membranes in the innervated portion of the electrocytes.

\section{Characterization of recombinant NSIST}

To better understand the nature of NSIST, we next characterized its expression in transfected COS cells. Figure $4 B$ shows an immunoblot of membranes from COS cells transfected with cDNA encoding NSIST (lane 2) or an irrelevant polypeptide (LNGFR, lane 1), probed with the RG211 antiserum. A polypeptide migrating at $\sim 118 \mathrm{kDa}$ was detected only in the NSISTtransfected cells. This polypeptide also has the slightly diff use appearance characteristic of glycosylated proteins.

To determine the relationship of NSIST to the mAb 3B3 epitope, we double labeled transfected COS cells with antiNSIST antiserum RG211 and mAb 3B3 (Fig. 5). MAb 3B3, but not RG211, labeled unpermeabilized cells, indicating that the MAb3B3 epitope is extracellular. On the other hand, NSIST
B. Transfected cos:

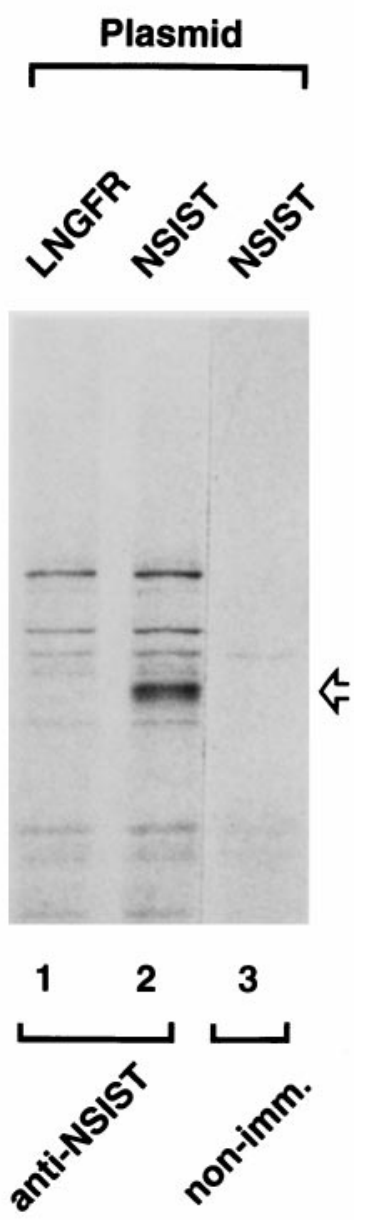

Figure 4. Characterization of native and recombinant NSIST polypeptides. A, Torpedo electric organ membrane fractions enriched in either synaptic or nonsynaptic components were separated by SDS-PAGE, blotted onto nitrocellulose, and probed with anti-NSIST antiserum RG212 (lanes 1-5). Membrane fractions enriched in synaptic components were used intact (lanes 1, 3, 5) or after extraction at $\mathrm{pH} 11$ (lane 2). A single prominent polypeptide of $\sim 136$ $\mathrm{kDa}$ is revealed (solid arrow), which persists after high $\mathrm{pH}$ extraction of the membranes. The polypeptide is not detected in membrane fractions enriched in nonsynaptic components (lane 4 ) or in control synaptic fractions probed with nonimmune serum (lane 5). B, Membranes from COS cells transfected with cDNA encoding NSIST (lane 2) or an irrelevant polypeptide (LNGFR, lane 1) and probed with anti-NSIST antiserum RG211. A major polypeptide of $\sim 118$ $\mathrm{kDa}$ is only detected in cells transfected with NSIST cDNA (open arrow). This polypeptide was not visualized when blots of NSIST-transfected cells were probed with nonimmune serum (lane 3).

immunoreactivity was only detected in permeabilized cells. To compare the subcellular distributions of these antigens in same cell, intact cells were first immunostained with mAb 3B3, then permeabilized and labeled with anti-NSIST. Figure 5 shows that $\mathrm{mAb} 3 \mathrm{~B} 3$ labels the cell surface in a punctate pattern, whereas anti-NSIST shows bright internal staining. Under any conditions tested, no staining of untransfected cells was observed with either reagent.

Notably, only a subset of the mAb-3B3-positive COS cells expressed NSIST. Counts of the stained cells showed that, although labeling of the positive cells was well above the threshold of detectability, approximately threefold more cells were positive for $\mathrm{mAb} 3 \mathrm{~B} 3$ than for anti-NSIST. The fact that more cells stain for $\mathrm{mAb} 3 \mathrm{~B} 3$ than for anti-NSIST suggests that the product(s) of NSIST, and/or NSIST itself, are secreted. Furthermore, these findings support the hypothesis that the NSIST cDNA encodes an enzyme responsible for producing an essential part of the mAb 3B3 epitope.

The above data indicate that NSIST is an enzyme that modifies endogenous COS cell substrates to create the $3 \mathrm{~B} 3$ epitope; moreover, the sequence homology of NSIST suggests that this activity involves sulfation. To test this proposal, we transfected COS cells with plasmids encoding either NSIST or an irrelevant polypeptide (LNGFR) and measured incorporation of ${ }^{35} \mathrm{SO}_{4}$. For both membrane and cytosolic COS fractions, counts were $8-10 \%$ higher for NSIST- than for LNGFR-transfected samples. These differences 

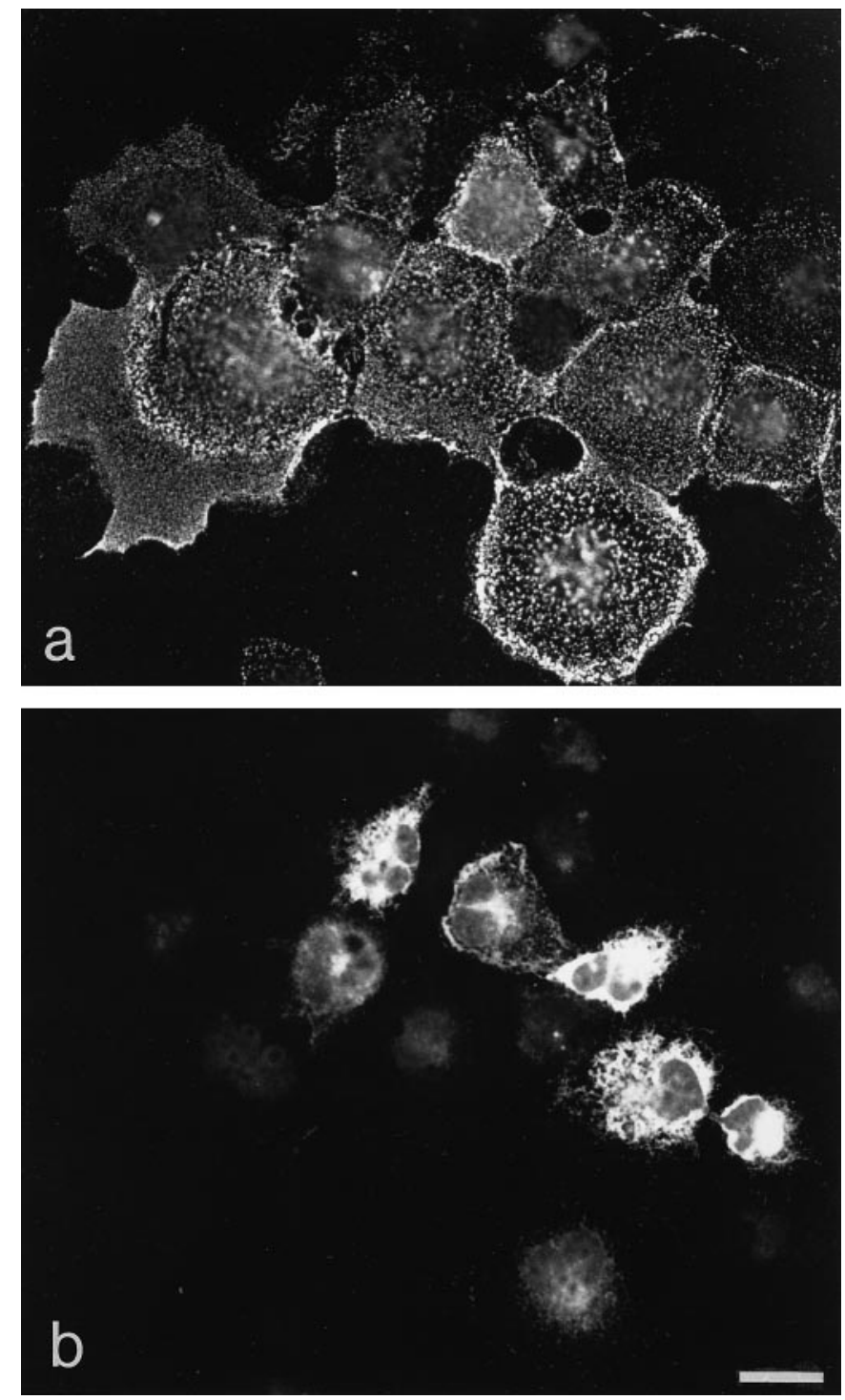

Figure 5. NSIST-transfected COS cells show different staining distributions for NSIST and $\mathrm{mAb} 3 \mathrm{~B} 3$. Living NSIST-transfected COS cells were incubated with $\mathrm{mAb} 3 \mathrm{~B} 3$, then fixed, permeabilized and double labeled with anti-NSIST antiserum RG211. Two distinct staining patterns emerge, with mAb 3B3 labeling the transfected cell surfaces in a punctate manner $(a)$ and RG211 showing bright internal staining of only a subset of the mAb-3B3-positive cells $(b)$. Transfected cells labeled with nonimmune serum show no staining (data not shown). Scale bar, $20 \mu \mathrm{m}$.

indicate that NSIST expression in COS cells is accompanied by elevated sulfate incorporation into membranous as well as cytosolic fractions.

\section{Chondroitin sulfate-like immunoreactivity is increased in NSIST-transfected COS cells}

The finding that NSIST has a high degree of homology to a C6ST suggests that NSIST may modify CSPGs. To investigate this possibility we used mAb CS-56, an antibody that recognizes chondroitin sulfate (CS), to probe immunoblots of transfected COS membrane fractions. Figure 6 shows that CS-56 labels a broad polydispersed band spanning $\sim 60-200 \mathrm{kDa}$ in NSISTtransfected COS membranes. There were also several discrete polypeptides in this region that showed increased CS-56 immunoreactivity in transfected cells. This finding indicates that CS is

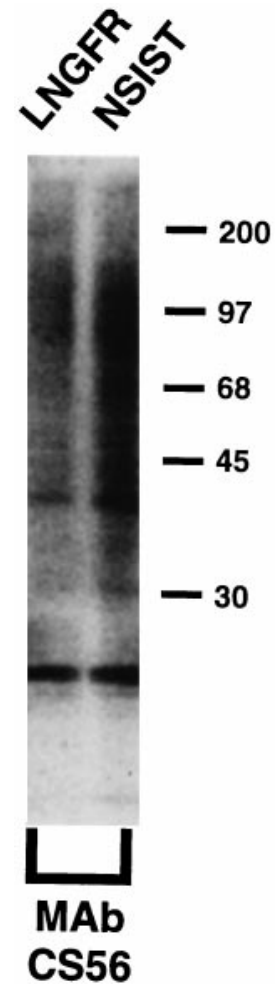

Figure 6. Transfection with NSIST cDNA increases mAb CS-56 immunolabeling to COS cell membrane fractions. COS cells were transfected with NSIST cDNA or with an irrelevant cDNA (LNGFR). Cell membranes were separated by SDS-PAGE on a $5-15 \%$ gradient gel, transferred to nitrocellulose, and probed with anti-CS mAb CS-56. A broad band spanning $\sim 60-200 \mathrm{kDa}$ is prominent in the NSIST-transfected sample, but only weakly visible in membranes from the nontransfected cells. Some additional bands are also specifically labeled in the NSIST lane. There was no labeling when irrelevant IgM was used as the primary antibody (data not shown).

a substrate for NSIST. Furthermore, the labeling of additional bands in the NSIST lane suggests that the enzyme may act at other structurally related sites, perhaps including the 3B3 epitope (see Discussion).

\section{Immunolocalization of NSIST in the nervous system}

We next investigated the cellular localization of NSIST in the intact nervous system. In Torpedo electric organ, NSIST-like immunoreactivity is concentrated in large puncta (Fig. 7A,C). Finely stained filaments extending away from the electrocyte membranes were also occasionally observed. Double labeling of AChRs with rh-BTx (Fig. 7B) shows that NSIST-rich puncta are associated with the innervated and, to a lesser extent, the noninnervated portions of the electrocytes and are likely to be intracellular. No staining was observed if nonimmune serum was substituted for anti-NSIST antiserum (Fig. 8A). MAb 3B3 labeling, in contrast to the NSIST immunoreactivity, included cell surfaces as well as fine granular material that filled the spaces between the tiers of electrocytes (Fig. 7D).

In sections of spinal cord, we observed NSIST immunolabeling of a compact cluster of large neuronal cell bodies in the ventral horn (Fig. 9). No labeling was detected in control sections (Fig. $9 B)$. The size and location of the NSIST-stained cells indicates that they are motor neurons. The staining is intracellular and is concentrated in small patches throughout the cytoplasm. Much of this staining is likely to represent material in the Golgi apparatus, 

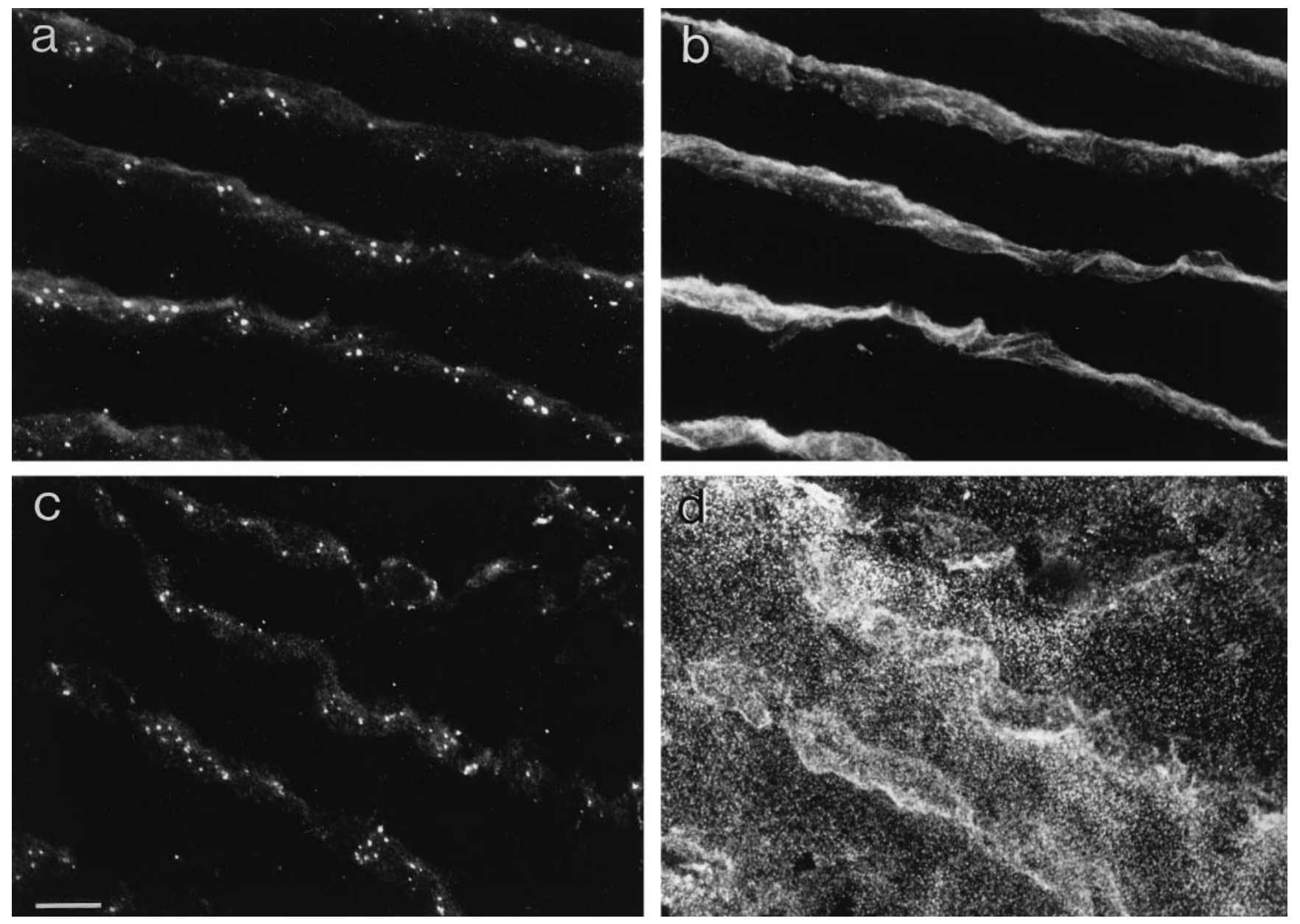

Figure 7. NSIST and the mAb 3B3 epitope have distinct distributions in Torpedo electric organ. Frozen sections from Torpedo electric organ were double labeled with anti-NSIST antiserum RG212 $(a)$ and rh-BTx $(b)$ or with RG212 $(c)$ and mAb 3B3 $(d)$. NSIST-like immunoreactivity $(a, c)$ is distributed in large puncta, most of which are associated with the innervated portion of the electrocytes. The latter is identified by bright staining with rh-BTx $(b)$. The mAb 3B3 epitope is associated with electrocyte surfaces $(d)$ and is also found between the tiers of cells. Scale bar, $20 \mu \mathrm{m}$.

because the NSIST staining pattern was indistinguishable from that observed for agrin (data not shown), a protein known to be concentrated in this subcellular compartment in these cells (Magill-Solc and McMahan, 1988).

We also examined the electromotor nucleus of the electric lobe, which contains the neurons innervating the electric organ. In coronal sections of electric lobe, we observed strong anti-NSIST immunostaining within neuronal cell bodies (Fig. 10A). No immunolabeling was detected in control sections (data not shown). As in the spinal cord motor neurons, this staining has a patchy cytoplasmic distribution suggestive of an association with Golgi membranes.

\section{B3 immunostaining has a unique distribution in the electric lobe}

We next wanted to know whether the product of the activity of NSIST was also expressed in the CNS. Monoclonal antibody 3B3 immunolabeling reveals marked extracellular staining in the electromotor nucleus (Fig. 10B). There is punctate staining on the surfaces of neuronal cell bodies, best seen as the focal plane is changed. In addition, another prominent form of staining consists of a reticular pattern in the parenchyma between neurons. Taken together, these distributions strongly suggest that glycoconjugates modified by NSIST are associated with the surfaces of
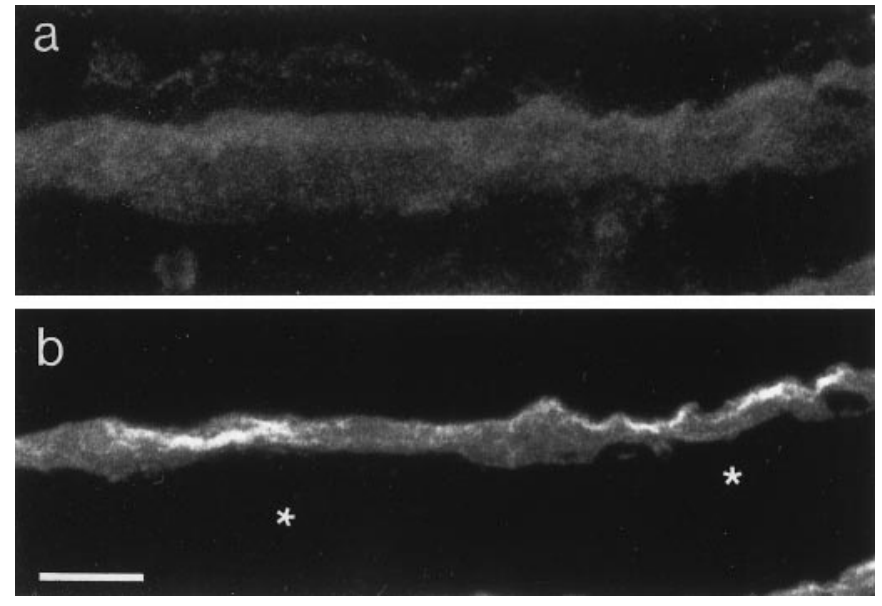

Figure 8. Controls for the specificity of Torpedo electric organ immunostaining. Sections of electric organ were incubated with nonimmune rabbit serum $(a)$ under the same conditions used in Figure 7. The innervated portion of a segment of electrocyte is revealed by rh-BTX staining $(b)$. The lower boundary of the noninnervated portion of the electrocyte is indicated by the asterisks in $B$. In contrast to the specific signal observed for anti-NSIST RG212 immunoreactivity (Fig. 7), no specific immunolabeling was observed under these control conditions. Scale bar, $20 \mu \mathrm{m}$. 

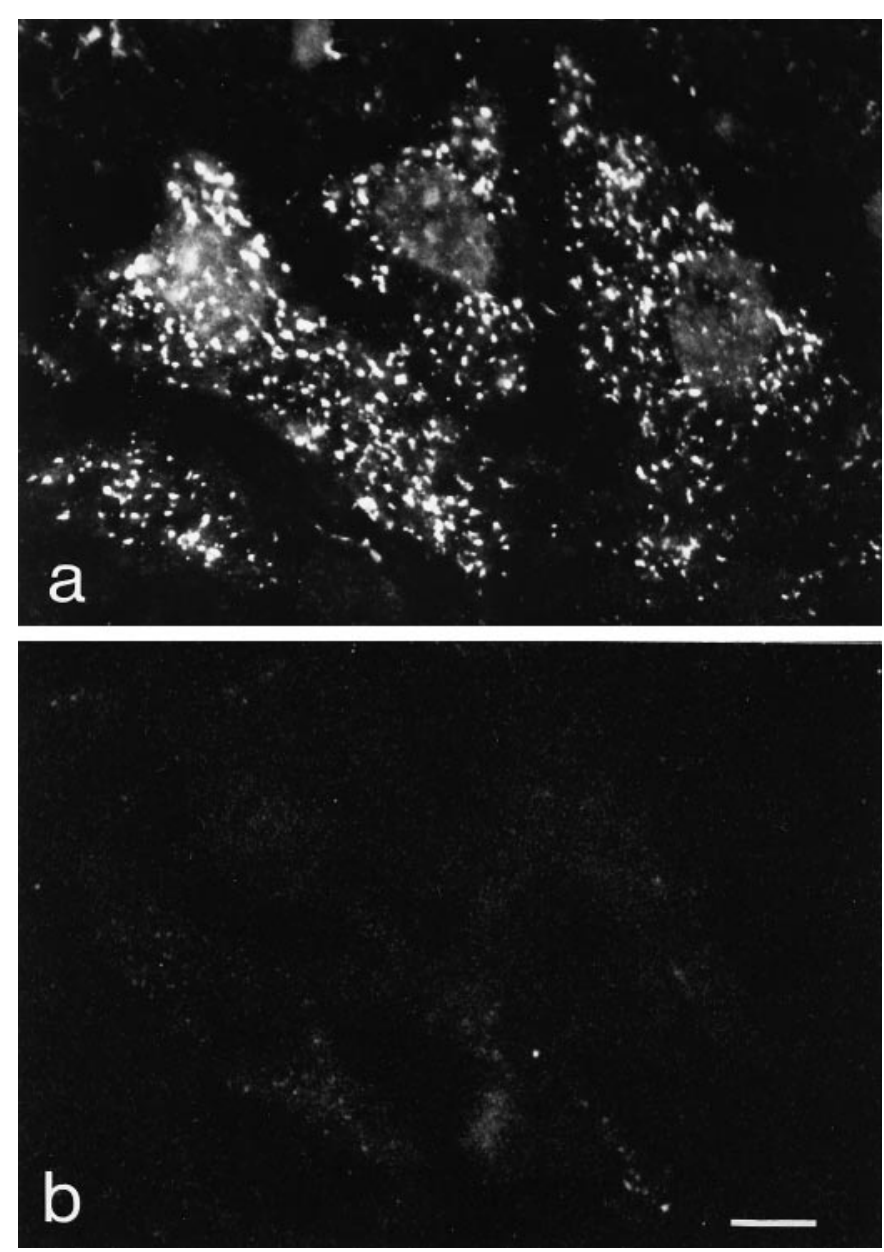

Figure 9. NSIST is distributed within the cell bodies of motor neurons. Transverse cryostat sections of Torpedo spinal cord were stained with anti-NSIST antiserum RG212 (a). RG212 labeling revealed an extensive, patchy, cytoplasmic distribution of NSIST within motor neuron cell bodies. The staining pattern suggests an association with the Golgi apparatus. A similar section labeled with nonimmune serum $(b)$ shows no staining. Scale bar, $20 \mu \mathrm{m}$.

neuronal cell bodies, as well as the extracellular matrix and neuropil in the CNS.

\section{DISCUSSION}

Posttranslational processing occurs for many synaptic components; however, a full understanding of such molecular modification requires characterizing the pertinent synthetic enzymes. We sought to elucidate the synthesis of the synapse-associated 3B3 epitope, known to contain sialidase-sensitive carbohydrate constituents. Using $\mathrm{mAb} 3 \mathrm{~B} 3$ as an expression-cloning probe, we isolated a novel cDNA clone encoding a polypeptide that is enriched in the nervous system of Torpedo. This polypeptide has sequence homology to several sulfotransferases, including a chondroitin sulfotransferase. The polypeptide, NSIST, is abundantly expressed by motor neurons and neurons of the electromotor nucleus. Moreover, the cytoplasmic localization of NSIST differs markedly from the extracellular distribution of the 3B3 epitope. NSIST is the first sulfotransferase shown to be expressed by a specific set of neurons. Furthermore, the distinct subcellular localization of neuronal NSIST together with the localization of its product(s) in the neuropil, suggests a role for NSIST in regulating cell-cell interactions, particularly at synapses, through the posttranslational processing of specific neuronal constituents.

Analysis of the deduced amino acid sequence of NSIST provides several clues about the structure of the polypeptide. The single 14-amino acid hydrophobic domain near the $\mathrm{N}$ terminus (Fig. $1 A$ ) is characteristic of a type II transmembrane-associated protein in which the signal sequence is retained as a Golgi retention signal (Wickner and Lodish, 1985). Our finding that NSIST resists extraction at $\mathrm{pH} 11$ also suggests that this hydrophobic domain is part of the mature polypeptide. The cationic amino acid residues flanking the transmembrane domain are typical of type II transmembrane proteins. Notably, this transmembrane domain is shorter than the canonical type II domain, which contains at least 17 amino acids (Klein et al., 1985). A similarly short transmembrane domain has been observed for the chicken C6ST by Fukuta et al. (1995), who further found that the cleavage site for generating a soluble form of the C6ST falls within this domain.

Our evidence indicates that the NSIST product(s) are secreted in cultured cells. Double labeling of transfected COS cells with anti-NSIST antiserum and mAb 3B3 showed internal NSIST immunoreactivity but external mAb 3B3 labeling. Furthermore, many more cells were positive for mAb 3B3 than for RG211, indicating that the product(s) of the activity of NSIST may be secreted and able to bind remote sites. Alternatively, it is possible that a secreted form of NSIST, not detectable with our antisera, could modify substrates on the surface of nontransfected cells. In fact, the cleaved, soluble form of C6ST is fully active in vitro (Habuchi et al., 1993). Whatever the mechanism, the predominantly intracellular expression of the enzyme and the extracellular localization of its product are in good agreement with their distribution in the nervous system (see below).

NSIST itself is likely to be a glycoprotein. The predicted polypeptide contains four potential N-linked glycosylation sites. One or more of these sites probably bears carbohydrate side chains: the polypeptide shows a diffuse appearance on immunoblots, and the apparent molecular weight of Torpedo NSIST as judged by SDS-PAGE is $136 \mathrm{kDa}$, whereas the predicted molecular weight is $51 \mathrm{kDa}$. This difference is unlikely to be attributable to alternative splicing, because NSIST in transfected COS cells has an apparent molecular weight of $118 \mathrm{kDa}$, although the transfected insert encodes a polypeptide with the predicted molecular weight of $51 \mathrm{kDa}$. It is more likely that the discrepancies between the deduced and observed molecular weights are largely attributable to the decreased SDS-binding (and thus slower mobility) characteristic of many glycoproteins (Deyst et al., 1995; Radeke et al., 1987). It is also possible that NSIST is subject to additional, as yet unknown, posttranslational modifications.

Several lines of evidence indicate that NSIST is a sulfotransferase. First, the features of the transmembrane domain of NSIST noted above are characteristic of this class of enzymes; moreover, NSIST contains significant additional homologies to several sulfotransferases. Second, ${ }^{35} \mathrm{SO}_{4}$ incorporation was increased in both membrane and cytosolic fractions from NSIST-transfected COS cells. In fact, the $8-10 \%$ increase that we measured is likely to represent an underestimate, because only a fraction of the cells picked up and expressed transfected plasmid. Finally, chondroitin sulfate expression is increased in NSIST-transfected COS cells as judged by immunolabeling with mAb CS-56, which recognizes some sulfate-containing moieties of CS (Avnur and Geiger, 1984).

NSIST is likely to modify other substrates in addition to CS. The mAb-3B3 epitope, which is created by NSIST, is sensitive to 

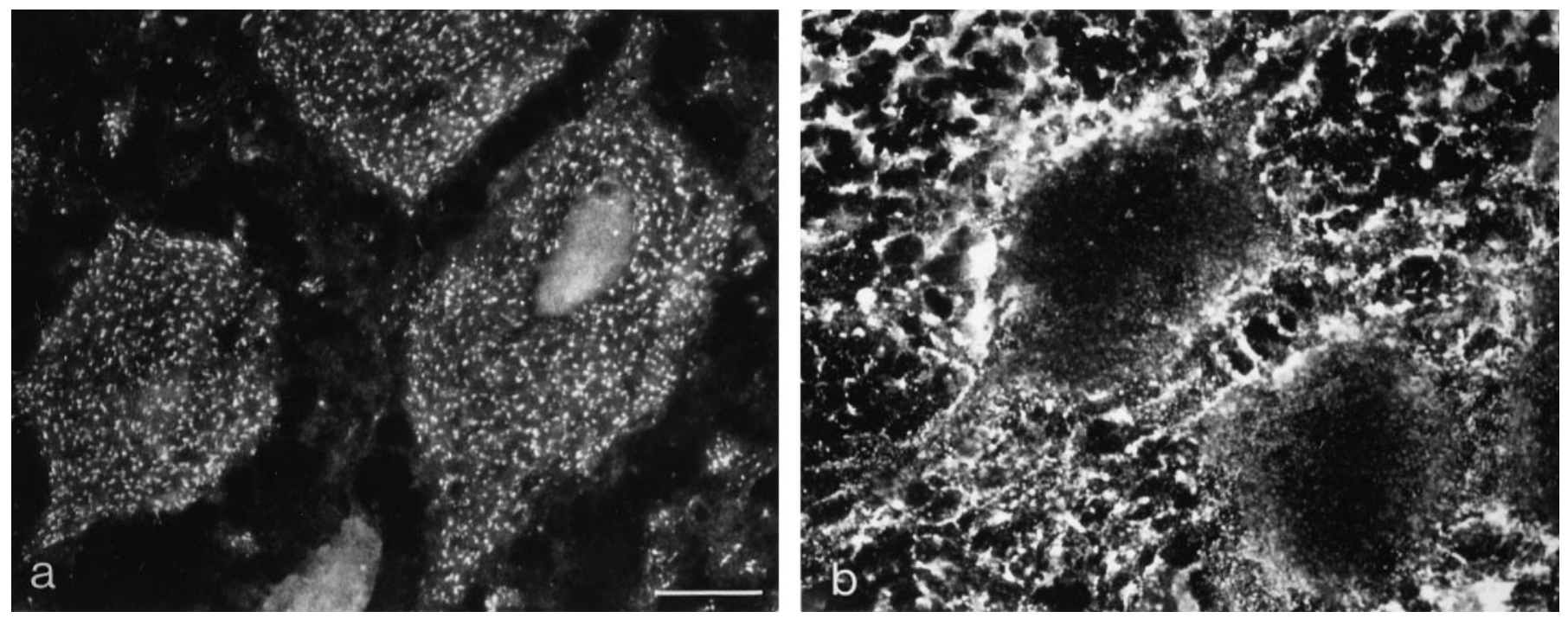

Figure 10. NSIST and the mAb-3B3 epitope have distinct localizations in neurons and neuropil of the Torpedo electromotor nucleus. Cryostat sections containing the electromotor nucleus of the Torpedo electric lobe were stained with anti-NSIST antiserum RG212 (a); neighboring sections were immunostained with mAb 3B3 (b). RG212 shows abundant patchy cytoplasmic staining throughout the neuronal cell bodies in the electromotor nucleus, indicating an association with the Golgi apparatus. No staining was seen in control sections. The 3B3 epitope has a punctate distribution on the surfaces of these cell bodies. In addition, between the cell bodies there is bright $3 \mathrm{~B} 3$ immunostaining associated with the neuropil of the electromotor nucleus. Scale bar, $20 \mu \mathrm{m}$.

sialidase, but not chondroitinase, digestion (Bowe et al., 1994). This epitope is thus likely to include sulfated moieties in close proximity to sialic acid. Such apposition is akin to that seen for the HNK-1 epitope, which contains both sialic acid and sulfated oligosaccharides (Field et al., 1992). Notably, C6ST can transfer sulfate to position 6 of the galactose residue in three known molecular contexts: (1) $N$-acetylgalactosamine (GalNAc) in CS (Habuchi et al., 1993); (2) galactose in keratan sulfate (Sugumaran et al., 1995; Habuchi et al., 1996); and (3) galactose in sialyl lactosamine oligosaccharides (SiaAc $\alpha 2-3 \mathrm{Gal} \beta 1-4 \mathrm{GlcNAc}$; Habuchi et al., 1997). Taken together with the data presented here, it seems likely that NSIST may act in more than one context to produce unique sulfate-containing moieties. One such substrate may be $\alpha$-dystroglycan, which bears abundant mAb-3B3 epitopes and which contains $\operatorname{Sia} \alpha 2-3 \mathrm{Gal} \beta 1-\mathrm{GlcNAc}$ as its major sialylated $o$-glycosidically linked oligosaccharide and is likely to be sulfated (Bowe et al., 1994; Smalheiser and Kim, 1995; Chiba et al., 1997).

Although NSIST is structurally related to the C6ST synthesized by chick chondrocytes, it seems likely to be a distinct enzyme. In addition to its remarkably selective expression in nervous tissue, one domain of NSIST shows greatly reduced homology to C6ST (Fig. 2A). It is possible that this domain is important for substrate specificity. Indeed, in preliminary experiments we have observed that COS cells transfected with C6ST do not express the mAb 3B3 epitope (B. McKechnie, M. Nastuk, O. Habuchi, and J. Fallon, unpublished observations).

To our knowledge NSIST is the first sulfotransferase demonstrated to be synthesized by neurons. A galactocerebroside sulfotransferase involved in myelin sulfatide synthesis is localized to oligodendrocyte and Schwann cell Golgi membranes (Benjamins et al., 1982; Tennekoon et al., 1983), but this enzyme lacks sequence homology to NSIST (Honke et al., 1997). A glucuronyl glycolipid sulfotransferase is enriched in gray matter (Chou and Jungalwala, 1993) and may be involved in creating the HNK-1 epitope. However, its homology to NSIST cannot be assessed, because the primary structure of this sulfotransferase is unknown.
In Torpedo electric organ, NSIST is expressed predominantly in the synaptic portion of the electrocyte. This distribution is consistent with the idea that the products of NSIST play a role at synapses. Indeed, the 3B3 epitope is selectively expressed in postsynaptic membrane fractions from this tissue (Bowe et al., 1994). NSIST is also enriched in these fractions. However, our immunolocalization data indicate that this enzyme is probably not a component of the AChR-rich, postsynaptic membranes, but rather of intracellular membranes that cofractionate with them. The punctate immunostaining observed in the electrocytes is similar to that observed by Jasmin et al. (1992) for Rab6p, which is a component of Golgi and post-Golgi vesicles in these cells. The clearly Golgi-like distribution seen in motor neurons is also consistent with such an intracellular localization. On the other hand, some carbohydrate-modifying enzymes are expressed on the postsynaptic membrane (see below). In this regard it will be important in future work to determine the localization of NSIST at the ultrastructural level.

A potential role for NSIST in the CNS is suggested by its localization to the neurons of the electromotor nucleus. Here, NSIST is distributed in an array that includes the Golgi apparatus, indicating that these neurons synthesize the enzyme. On the other hand, mAb 3B3 labels the surfaces of these neurons as well as the neuropil between them. Thus, the products of NSIST (or NSIST itself), may be locally secreted, allowing for involvement in cell-cell interactions intrinsic to the CNS. This latter possibility may be relevant to the finding that specific subsets of neurons in the mammalian CNS express a perineuronal CSPG (Lander et al., 1997). Furthermore, cultured cortical neurons produce an entirely extracellular, surface-associated CSPG that may constitute a neuronally derived component of the extracellular matrix (Lander et al., 1998).

The expression of NSIST in Torpedo motor neurons provides a mechanism for synapse-specific sulfation at the neuromuscular junction. In this regard, it is noteworthy that synaptic CS has been implicated in the formation of neuromuscular junctions. $\mathrm{C} 2 \mathrm{mus}-$ cle cells require surface $\mathrm{CS}$ to produce spontaneous AChR 
clusters in culture (Mook-Jung and Gordon, 1995). The S27 variant of C2 cells, which exhibits reduced incorporation of sulfate into proteoglycans (Gordon and Hall, 1989), are unable to form spontaneous or agrin-induced AChR clusters (Gordon et al., 1993). Notably, S27 cells can form AChR clusters when cocultured with motor neurons (Gordon et al., 1993). Thus, the production of NSIST by motor neurons could distinguish synaptic from extrasynaptic CS through differential sulfation, an interesting possibility given the view that the degree of sulfation of synaptic CS is probably important to its function (Mook-Jung and Gordon, 1995; Bowen et al., 1996). Although we did not observe elevated NSIST levels at neuromuscular junctions, it is noteworthy that a specialized Golgi apparatus exists just under the postsynaptic membrane (Ralston et al., 1993; Antony et al., 1995). It is thus feasible that NSIST is also selectively expressed at junctional nuclei in muscle. Although undetectable in our Northern blots, any NSIST mRNA associated with this relatively small population of nuclei should be readily demonstrable with in situ hybridization.

A selective activity of NSIST at synapses would add an intriguing dimension to the molecular interplay of synaptogenesis. We would expect this sulfotransferase to act in coordination with other enzymes responsible for posttranslational processing. Notably, a specific postsynaptic localization has been demonstrated for GalNAc-terminated carbohydrates (Martin and Sanes, 1995) as well as for a muscle-derived GalNAc transferase (Scott et al., 1990). Furthermore, coordinated expression has been observed for a GalNAc transferase and its companion sulfotransferase in several tissues, including brain (Dharmesh et al., 1993). NSIST, as the first sulfotransferase shown to be synthesized by specific types of neurons, is a promising candidate to participate in synapsespecific sulfation of particular carbohydrate moieties. In this light, it will be important to show whether NSIST interacts with enzymes such as GalNAc transferase in the coordination of synapsespecific posttranslational processing.

\section{REFERENCES}

Altschul SF, Gish W, Miller W, Myers EW, Lipman DJ (1990) Basic local alignment search tool. J Mol Biol 215:403-410.

Anderson MJ, Fambrough DM (1983) Aggregates of acetylcholine receptors are associated with plaques of a basal lamina heparan sulfate proteoglycan on the surface of skeletal muscle fibers. J Cell Biol 97:1396-1411.

Antony C, Huchet M, Changeux JP, Cartaud J (1995) Developmental regulation of membrane traffic organization during synaptogenesis in mouse diaphragm muscle. J Cell Biol 130:959-968.

Avnur Z, Geiger B (1984) Immunocytochemical localization of native chondroitin-sulfate in tissues and cultured cells using specific monoclonal antibody. Cell 38:811-822.

Bayne EK, Anderson MJ, Fambrough DM (1984) Extracellular matrix organization in developing muscle: correlation with acetylcholine receptor aggregates. J Cell Biol 99:1486-1501.

Benjamins JA, Hadden T, Skoff RP (1982) Cerebroside sulfotransferase in Golgi-enriched fractions from rat brain. J Neurochem 38:233-241.

Bowe MA, Deyst KA, Leszyk JD, Fallon JR (1994) Identification and purification of an agrin receptor from Torpedo postsynaptic membranes: a heteromeric complex related to the dystroglycans. Neuron 12:1173-1180.

Bowen DC, Gordon H, Hall ZW (1996) Altered glycosaminoglycan chain structure in a variant of the $\mathrm{C} 2$ mouse muscle cell line. J Neurochem 66:2580-2588.

Chiba A, Matsumura K, Yamada H, Inazu T, Shimizu T, Kusunoki S, Kanazawa I, Kobata A, Endo T (1997) Structures of sialylated O-linked oligosaccharides of bovine peripheral nerve $\alpha$-dystroglycan. J Biol Chem 272:2156-2162.

Chiu AY, Ko J (1994) A novel epitope of entactin is present at the mammalian neuromuscular junction. J Neurosci 14:2809-2817.
Chou DKH, Jungalwala FB (1993) Characterization and developmental expression of a novel sulfotransferase for the biosynthesis of sulfoglucuronyl glycolipids in the nervous system. J Biol Chem 268:330-336.

Davis S, Aldrich TH, Valenzuela DM, Wong V, Furth ME, Squinto SP, Yancopoulos GD (1991) The receptor for ciliary neurotrophic factor. Science 253:59-63.

Deyst KA, Bowe MA, Leszyk JD, Fallon JR (1995) The $\alpha$-dystroglycan$\beta$-dystroglycan complex: membrane organization and relationship to an agrin receptor. J Biol Chem 270:25956-25959.

Dharmesh SM, Skelton TP, Baenziger JU (1993) Co-ordinate and restricted expression of the ProXaaArg/Lys-specific GalNActransferase and the GalNAc $\beta 1,2 \mathrm{Man} \alpha$-4-sulfotransferase. J Biol Chem 268:17096-17102.

Emerling DE, Lander AD (1996) Inhibitors and promoters of thalamic neuron adhesion and outgrowth in embryonic neocortex: functional association with chondroitin sulfate. Neuron 17:1089-1100.

Fallon JR, Nitkin RM, Reist NE, Wallace BG, McMahan UJ (1985) Acetylcholine receptor-aggregating factor is similar to molecules concentrated at neuromuscular junctions. Nature 315:571-574.

Field MC, Wing DR, Dwek RA, Rademacher TW, Schmitz B, Bollensen E, Schachner M (1992) Detection of multisulphated N-linked glycans in the L2/HNK-1 carbohydrate epitope expressing neural adhesion molecule $\mathrm{P}_{0}$. J Neurochem 58:993-1000.

Fryer HJL, Hockfield S (1996) The role of polysialic acid and other carbohydrate polymers in neural structural plasticity. Curr Opin Neurobiol 6:113-118.

Fukuta M, Uchimura K, Nakashima K, Kato M, Kimata K, Shinomura T, Habuchi O (1995) Molecular cloning and expression of chick chondrocyte chondroitin-6-sulfotransferase. J Biol Chem 270:18575-18580.

Gordon H, Hall ZW (1989) Glycosaminoglycan variants in the C2 muscle cell line. Dev Biol 135:1-11.

Gordon H, Lupa M, Bowen D, Hall ZW (1993) A muscle cell variant defective in glycosaminoglycan biosynthesis forms nerve-induced but not spontaneous clusters of the acetylcholine receptor and the $43 \mathrm{kDa}$ protein. J Neurosci 13:586-595.

Habuchi O, Matsui Y, Kotoya Y, Aoyama Y, Yasuda Y, Noda M (1993) Purification of chondroitin 6-sulfotransferase secreted from cultured chick embryo chondrocytes. J Biol Chem 268:21968-21974.

Habuchi O, Hirahara Y, Uchimura K, Fukuta M (1996) Enzymatic sulfation of galactose residue of keratan sulfate by chondroitin 6-sulfotransferase. Glycobiology 6:51-57.

Habuchi O, Suzuki Y, Fukuta M (1997) Sulfation of lactosamine oligosaccharides by chondroitin 6-sulfotransferase. Glycobiology 7:405-412.

Honke K, Tsuda M, Hirahara Y, Ishii A, Makita A, Wada Y (1997) Molecular cloning and expression of cDNA encoding human $3^{\prime}$-phosphoadenylylsulfate:galactosylceramide $3^{\prime}$-sulfotransferase. J Biol Chem 272:4864-4868.

Jasmin BJ, Goud B, Camus G, Cartaud J (1992) The low molecular weight guanosine triphosphate-binding protein Rab6p associates with distinct post-Golgi vesicles in Torpedo marmorata electrocytes. Neuroscience 49:849-855.

Klein P, Kanehisa M, DeLisi C (1985) The detection and classification of membrane-spanning proteins. Biochim Biophys Acta 815:468-476.

Lander C, Kind P, Maleski M, Hockfield S (1997) A family of activitydependent neuronal cell-surface chondroitin sulfate proteoglycans in the cat visual cortex. J Neurosci 17:1928-1939.

Lander C, Zhang H, Hockfield S (1998) Neurons produce a neuronal cell surface-associated chondroitin sulfate proteoglycan. J Neurosci 18:174-183.

Magill-Solc C, McMahan UJ (1988) Motor neurons contain agrin-like molecules. J Cell Biol 107:1825-1833.

Martin PT, Sanes JR (1995) Role for a synapse-specific carbohydrate in agrin-induced clustering of acetylcholine receptors. Neuron 14:743-754.

Mook-Jung I, Gordon H (1995) Acetylcholine receptor clustering in C2 muscle cells requires chondroitin sulfate. J Neurobiol 28:482-492.

Neubig RR, Krodel EK, Boyd ND, Cohen JB (1979) Acetylcholine and local anesthetic binding to Torpedo nicotinic postsynaptic membranes after removal of nonreceptor peptides. Proc Natl Acad Sci USA 76:690-694.

Otterness DM, Her C, Aksoy S, Kimura S, Wieben ED, Weinshilboum RM (1995) Human dehydroepiandrosterone sulfotransferase gene: molecular cloning and structural characterization. DNA Cell Biol 14:331-341. 
Radeke MJ, Misko TP, Hsu C, Herzenberger LA, Shooter EM (1987) Gene transfer and molecular cloning of the rat nerve growth factor receptor. Nature 325:593-597.

Ralston E (1993) Changes in architecture of the Golgi complex and other subcellular organelles during myogenesis. J Cell Biol 120:399-409.

Rikke BA, Roy AK (1996) Structural relationships among members of the mammalian sulfotransferase gene family. Biochim Biophys Acta 1307:331-338.

Roche P, Debelle F, Maillet F, Lerouge P, Faucher C, Truchet G, Denarie J, Prome J-C (1991) Molecular basis of symbiotic host specificity in Rhizobium meliloti: nodH and nodPQ genes encode the sulfation of lipo-oligosaccharide signals. Cell 67:1131-1143.

Sambrook J, Fritsch EF, Maniatis T (1989) Molecular Cloning. Cold Spring Harbor, NY: Cold Spring Harbor.

Sanes JR, Schachner M, Covault J (1986) Expression of several adhesive macromolecules (N-CAM, L1, J1, NILE, uvomorulin, laminin, fibronectin, and a heparan sulfate proteoglycan) in embryonic, adult, and denervated skeletal muscle. J Cell Biol 102:420-431.

Sanes JR, Scheller RH (1997) Synapse formation: a molecular perspective. In: Molecular and cellular approaches to neural development
(Cowan WM, Jessell TM, Zipursky SL, eds), pp 179-219. New York: Oxford UP

Schachner M, Martini R (1995) Glycans and the modulation of neuralrecognition molecule function. Trends Neurosci 18:183-191.

Scott LJC, Balsamo J, Sanes JR, Lilen J (1990) Synaptic localization and neural regulation of an $N$-acetylgalactosaminyl transferase in skeletal muscle. J Neurosci 10:346-350.

Smalheiser NR, Kim E (1995) Purification of cranin, a laminin binding protein: identity with dystroglycan and reassessment of its carbohydrate moieties. J Biol Chem 270:15425-15433.

Sugumaran G, Katsman M, Drake RR (1995) Purification, photoaffinity labeling, and characterization of a single enzyme for 6-sulfation of both chondroitin sulfate and keratan sulfate. J Biol Chem 270:22483-22487.

Tennekoon G, Zarube M, Wolinsky J (1983) Topography of cerebroside sulfotransferase in golgi-enriched vesicles from rat brain. J Cell Biol 97:1107-1112.

Varin L, DeLuca V, Ibrahim RK, Brisson N (1992) Molecular characterization of two plant flavonol sulfotransferases. Proc Natl Acad Sci USA 89:1286-1290.

Wickner WT, Lodish HF (1985) Multiple mechanisms of protein insertion into and across membranes. Science 230:400-407. 